\title{
Frequency of TLR 2, 4, and 9 Gene Polymorphisms in Chinese Population and Their Susceptibility to Type 2 Diabetes and Coronary Artery Disease
}

\author{
Fengjing Liu, ${ }^{1,2}$ Weixin Lu, ${ }^{1}$ Qiaohui Qian, ${ }^{1}$ Weigang Qi, ${ }^{3}$ Jifan Hu, ${ }^{2}$ and Bo Feng1 \\ ${ }^{1}$ Department of Endocrinology, Tongji University, Affiliated East Hospital Tongji University, Shanghai 200120, China \\ ${ }^{2}$ Department of Medicine, Palo Alto Health Care System, Veterans Affairs, School of Medicine, Stanford University, Palo Alto, \\ CA 94304, USA \\ ${ }^{3}$ Department of Cardiology, Affiliated East HospitalTongji University, Tongji University, Shanghai 200120, China
}

Correspondence should be addressed to Jifan Hu, jifan@stanford.edu and Bo Feng, fengbo@medmail.com.cn

Received 10 June 2012; Accepted 27 July 2012

Academic Editor: Masamitsu Yamaguchi

Copyright (C) 2012 Fengjing Liu et al. This is an open access article distributed under the Creative Commons Attribution License, which permits unrestricted use, distribution, and reproduction in any medium, provided the original work is properly cited.

\begin{abstract}
Toll-like receptors (TLRs) are pivotal components of the innate immune response. Activation of the innate immune system and subsequent chronic low-grade inflammation are thought to be involved in the pathogenesis of atherosclerosis and type 2 diabetes. In the study, we genotyped TLRs gene polymorphisms, including TLR2 Arg677Trp and Arg753Gln, TLR4 Asp299Gly and Thr399Ile, TLR9-1486T/C and -1237T/C. The frequencies of TT, TC and CC genotype of TLR9-1486T/C mutation were $39.6 \%, 45.8 \%$ and $14.6 \%$, respectively; the frequencies of $\mathrm{T}$ allele and $\mathrm{C}$ allele were $62.5 \%$ and $37.5 \%$. However, neither of these parameters was statistically significant among study groups. In addition, we were surprised to find that the commonly reported TLR SNPs in the Western countries, like TLR2 Arg677Trp or Arg753Gln, TLR4 Asp299Gly or Thr399Ile and TLR9-1237T/C, were not polymorphic at all in all study subjects. In conclusion, our data suggests that TLR2 Arg677Trp or Arg753Gln, TLR4 Asp299Gly or Thr399Ile and TLR9-1237T/C polymorphisms have low frequency and TLR9-1486T/C polymorphism may not be a suitable marker in predicting the susceptibility to type 2 diabetes or coronary artery disease in the Chinese Han population.
\end{abstract}

\section{Introduction}

Coronary artery disease $(\mathrm{CAD})$ is the leading cause of death in men and women worldwide, particularly in the developed countries [1]. Type 2 diabetes mellitus, a major cause of cardiovascular morbidity and mortality in developed countries, has increased significantly in East Asia, like Chinese Han population, as the local economy improves significantly in the last decade. Although the primary cause for this increment remains unclear, the activation of innate immunity system and chronic low-grade inflammation may be plausibly involved [2]. Recent studies have suggested the role of certain genetic variants of innate immunity system in the predisposition to the development of the disease.

Toll-like receptors (TLRs) are the family of genetically conserved transmembrane receptors involved in the innate immunity and pathogen recognition. Recognition of pathogen-associated molecular patterns by TLRs activates signaling events that induce the expression of effector molecules, such as cytokines and chemokines, controlling the adaptive immune responses $[3,4]$.

Genetic variations within genes encoding these receptors have an important influence on the pathogenesis of inflammatory diseases [5]. Variations within genes of the family of innate immune receptors may account, in part, for the inherited differences in the susceptibility to autoimmune diseases or inflammatory disease. The ability of certain individuals to respond properly to TLR ligands may be impaired by single nucleotide polymorphisms (SNPs) within TLR genes, resulting in an altered susceptibility to the disease.

Considering the potential role of TLRs pathway in the overall immune reconstitution, we examined whether the altered immune response caused by TLRs gene variation was associated with type 2 diabetes and/or its macrovascular complications. We were particularly interested in comparing 


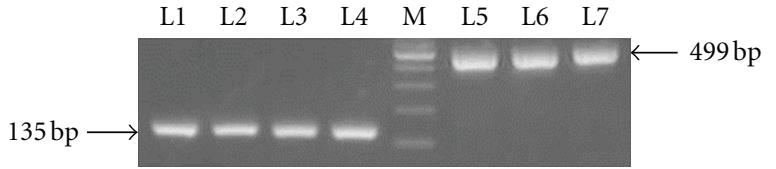

FIGURE 1: Electrophoretic result of TLR9 gene PCR products. $100 \mathrm{bp}$ DNA Ladder Marker is shown in lane M. TLR9 gene PCR products (TLR9-1237T/C = 135 bp, TLR9-1486T/C = 499bp) are shown respectively in lanes $1-4$ and lanes 5-7.

the role of TLR variations in subgroups of CAD patients with and without type 2 diabetes.

\section{Materials and Methods}

2.1. Study Subjects. A total of 432 subjects who underwent successfully percutaneous coronary intervention were consecutively recruited from the inpatient of Department of Cardiology at Tongji University Affiliated East Hospital between July 2008 and December 2009. Because the study was performed as a monocentric study, care was taken to avoid that any carriers of the polymorphisms studied were related to each other. All subjects were divided into two groups according to the presence $(n=333)$ or absence $(n=99)$ of CAD. And then patients with CAD were divided into two groups according to the presence ( $n=160)$ or absence $(n=173)$ of T2DM; the patients without $\mathrm{CAD}$ were also divided into two groups according to the presence $(n=33)$ or absence $(n=66)$ of T2DM. The diagnosis of diabetes mellitus was based on the definition and diagnostic criteria for diabetes mellitus of WHO (World Health Organization) in 1999. CAD was defined as the result of coronary angiography, which was performed via the radial or femoral artery. All the angiographies were interpreted with the consensus from two independent operators blind to the results of the genetic analysis. The diagnosis of CAD was based on $\geq 50 \%$ of luminal stenosis in at least one major coronary vessel. Clinical data (Table 1) consist of age, gender, body mass index (BMI), obesity (BMI $\geq$ $\left.25 \mathrm{~kg} / \mathrm{m}^{2}\right)$, hypertension $(\geq 140 / 90 \mathrm{mmHg}$ or any antihypertensive treatment), dyslipidaemia (according to NCEP-ATP III criteria or any antilipemic therapy), and smoking status ("ever" or "never," "ever" defined as having smoked more than three cigarettes a day for at least 1 year). Individuals were excluded if they had evidence of normal or nearly normal coronary arteries, congestive heart failure, valvular heart disease, cardiomyopathy, inflammatory or neoplastic condition, and hepatic or renal dysfunction.

2.2. Ethical Approval. All subjects gave written informed consent for the intervention and the genetic analyses, which was reviewed and approved by the Ethics Committees of Tongji University. This study was in accordance with the principles of the Helsinki Declaration (1964).

2.3. Genotyping. Blood samples from all subjects were collected in EDTA vials and stored at $-80^{\circ} \mathrm{C}$ until required.
Genomic DNA was isolated from frozen whole blood using the EZ-10 Spin Column Whole Blood Genomic DNA MiniPreps Kit (Sangon, Canada) according to the manufacturer's instructions. The alleles of TLR gene polymorphisms were detected using polymerase chain restriction-restriction fragment length polymorphism (PCR-RFLP) procedure.

PCR reactions were set up in a $25 \mu \mathrm{L}$ reaction volume containing $1.5 \mu \mathrm{L} 10 \mu \mathrm{M}$ forward primer, $1.5 \mu \mathrm{L} 10 \mu \mathrm{M}$ reverse primer, $1.5 \mu \mathrm{L}$ DNA extract, $12.5 \mu \mathrm{L}$ GoTaq Green Master Mix (Promega, USA), and $8.0 \mu$ L sterilized $\mathrm{dd}_{2} \mathrm{O}$. Reactions were run on a PTC-200 DNA Engine PCR (BIORAD, USA) using the following conditions: initial denaturation at $95^{\circ} \mathrm{C}$ for $5 \mathrm{~min}$ followed by 36 cycles of denaturation at $94^{\circ} \mathrm{C}$ for 40 seconds, annealing at $\mathrm{X}^{\circ} \mathrm{C}$ for 40 seconds, and extention at $72^{\circ} \mathrm{C}$ for 1 minute. A final extension step was at $72^{\circ} \mathrm{C}$ for 10 minute. The PCR products were held at $4^{\circ} \mathrm{C}$ until analysis. The primers and PCR conditions used to detect TLR variants were listed in Table 2. PCR products were electrophoresed in an agarose gel and visualized by ethidium bromide staining. TLR9 gene PCR products were shown in Figure 1.

The PCR products $(10 \mu \mathrm{L})$ were digested overnight or for $12-14 \mathrm{~h}$ at $37^{\circ} \mathrm{C}$ with $5 \mathrm{U}$ of restriction endonucleases: AciI for TLR2 Arg677Trp and Arg753Gln polymorphisms, NcoI for TLR4 Arg299Gly and HinfI for TLR4 Arg399Ile polymorphisms, and BstNI for TLR9-1237T/C and AflII for TLR9-1486T/C polymorphisms. Digested PCR products were separated by electrophoresis through $1 \%-2.5 \%$ agarose gel. After digestion, the wild-type allele sizes of TLR2 were $55 \mathrm{bp}, 147 \mathrm{bp}$, and $228 \mathrm{bp}$; the wild-type allele sizes of TLR4 did not change and they were $249 \mathrm{bp}$ for the Asp299 (A allele) and $406 \mathrm{bp}$ for the Thr399 (C allele); the wild-type allele sizes of TLR9-1237T/C polymorphism were $108 \mathrm{bp}$ and $27 \mathrm{bp}$; the wild-type allele sizes of TLR9-1486T/C polymorphism were $172 \mathrm{bp}$ and $327 \mathrm{bp}$. The sizes for polymorphic alleles were $283 \mathrm{bp}$ and $147 \mathrm{bp}$ for TLR2 Arg677Trp; $375 \mathrm{bp}$ and $55 \mathrm{bp}$ for TLR2 Arg753Gln; $223 \mathrm{bp}$ and $26 \mathrm{bp}$ for TLR4 299Gly ( $\mathrm{G}$ allele) and $377 \mathrm{bp}$ for TLR4 399Ile ( $\mathrm{T}$ allele); $60 \mathrm{bp}$, $48 \mathrm{bp}$, and $27 \mathrm{bp}$ for TLR9-1237T/C and $499 \mathrm{bp}$ for TLR91486T/C. Electrophoretic separation of TLR9 gene -1486T/C polymorphism was shown in Figure 2.

2.4. Statistical Analysis. All the statistical analyses were performed using the SPSS software for Windows version 16.0. Chi-square analysis was used to assess deviation from Hardy-Weinberg equilibrium (HWE) and to compare the genotype and allele frequency between groups. Analysis of variance was used to investigate associations with clinical or metabolic parameters. Multivariant analysis was done by ANOVA. A $P$ value $<0.05$ was considered statistically significant.

\section{Results}

Compared with non-CAD group, patients with CAD had higher incidence of DM (33/99 versus 160/333, $P<0.05$ ). Also, compared with non-DM group, patients with DM had higher incidence of CAD (173/239 versus160/193, $P<0.05)$. 
TABLE 1: Clinical characteristics among groups in study population.

\begin{tabular}{|c|c|c|c|c|c|}
\hline & Control & $\mathrm{CAD}$ & $\mathrm{DM}$ & $\mathrm{DM}+\mathrm{CAD}$ & $P$ \\
\hline$n$, male/female & $43 / 23$ & $113 / 60$ & $20 / 13$ & $95 / 65$ & $P=0.811^{*}$ \\
\hline Age, years & $60.3 \pm 8.0$ & $62.9 \pm 9.6$ & $61.6 \pm 8.7$ & $65.3 \pm 8.7$ & $P=0.165^{\dagger}$ \\
\hline Smoker, $n(\%)$ & $20(30.0 \%)$ & $76(43.9 \%)$ & $9(27.3 \%)$ & $58(36.2 \%)$ & $P=0.108^{*}$ \\
\hline Obesity, $n(\%)$ & $11(16.7 \%)$ & $21(12.1 \%)$ & $6(18.2 \%)$ & $26(16.2 \%)$ & $P=0.633^{*}$ \\
\hline Hypertention, $n(\%)$ & $29(43.9 \%)$ & $107(61.8 \%)$ & $17(51.5 \%)$ & $120(75.0 \%)$ & $P<0.005^{*}$ \\
\hline Dyslipidaemia, $n(\%)$ & $26(39.4 \%)$ & $93(53.8 \%)$ & $18(54.5 \%)$ & $97(60.4 \%)$ & $P=0.037^{*}$ \\
\hline
\end{tabular}

Data were means \pm SD or percentages $(\%) .{ }^{*} \chi^{2}$ test. ${ }^{\dagger}$ One-way ANOVA.

TABle 2: Primers, PCR conditions, and restriction enzymes used for genotyping TLRs gene.

\begin{tabular}{|c|c|c|c|c|c|c|}
\hline SNPs & & Primer sequence $5^{\prime}-3^{\prime}$ & AT & PCR product & $\mathrm{RE}$ & Expected product \\
\hline \multirow{3}{*}{ TLR2 } & Arg677Trp & F: TAT GGT CCA GGA GCT GGA GA & \multirow{3}{*}{$60^{\circ} \mathrm{C}$} & \multirow{3}{*}{$430 \mathrm{bp}$} & \multirow{3}{*}{ AciI } & Wt: $228 \mathrm{bp}$ \\
\hline & \multirow[b]{2}{*}{ Arg753Gln } & \multirow[b]{2}{*}{ R: TGA CAT AAA GAT CCC AAC TAG ACA A } & & & & \\
\hline & & & & & & $\begin{array}{l}\text { Arg67/Trp: } 283 \text { bp } \\
\text { Arg677Trp: } 375 \text { bp }\end{array}$ \\
\hline \multirow{4}{*}{ TLR4 } & \multirow{2}{*}{ Arg299Gly } & F: GAT TAG CAT ACT TAG ACT ACT ACC TCC ATG & \multirow{2}{*}{$55^{\circ} \mathrm{C}$} & \multirow{2}{*}{$249 \mathrm{bp}$} & \multirow{2}{*}{ NcoI } & Wt: $249 \mathrm{bp}$ \\
\hline & & R: GAT CAA CTT CTG AAA AAG CAT TCC CAC & & & & Mt: $223 \mathrm{bp}$ \\
\hline & \multirow{2}{*}{ Thr399Ile } & F: GGT TGC TGT TCT CAA AGT GAT TTT GGG AGA A & \multirow{2}{*}{$60^{\circ} \mathrm{C}$} & \multirow{2}{*}{$406 \mathrm{bp}$} & \multirow{2}{*}{ HinfI } & Wt: 406 bp \\
\hline & & R:A CCT GAA GAC TGG AGA GTG AGT TAA ATG CT & & & & Mt: $377 \mathrm{bp}$ \\
\hline \multirow{4}{*}{ TLR9 } & \multirow{2}{*}{$\mathrm{T}-1237 \mathrm{C}$} & F: ATG GGA GCA GAG ACA TAA TGG A & \multirow{2}{*}{$62^{\circ} \mathrm{C}$} & \multirow{2}{*}{$135 \mathrm{bp}$} & \multirow{2}{*}{ BstNI } & Wt: $108 \mathrm{bp}$ \\
\hline & & R: CTG CTT GCA GTT GAC TGT GT & & & & Mt: 60 bp 48 bp \\
\hline & \multirow{2}{*}{$\mathrm{T}-1486 \mathrm{C}$} & F: TCC CAG CAG CAA CAA TTC ATT A & \multirow{2}{*}{$62^{\circ} \mathrm{C}$} & \multirow{2}{*}{$499 \mathrm{bp}$} & \multirow{2}{*}{ AflII } & Wt: 327 bp \\
\hline & & R: CTG CTT GCA GTT GAC TGT GT & & & & Mt: 499 bp \\
\hline
\end{tabular}

F: forward primer; R: reverse primer; AT: annealing temperature; RE: restriction enzyme.

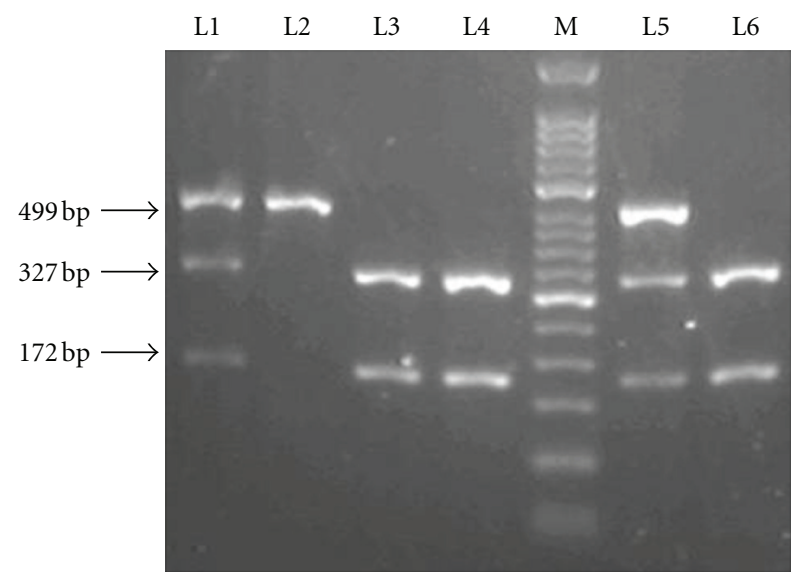

FIGURE 2: Electrophoretic separation of TLR9 gene PCR fragments after restriction endonuclease cleavage on a $2 \%$ agarose gel. Two heterozygous carriers are shown in lane 1 and 5. A homozygous mutation sample is shown in lane 2. Three wild-type samples are shown in lanes 3, 4, and 6. 50 bp DNA Ladder Marker is shown in lane $\mathrm{M}$.

In T2DM group, 14 of the 33 patients were heterozygotes for TLR9-1486T/C polymorphism and 6 were mutant homozygotes. In CAD group, 76 of the 173 patients were heterozygous for TLR9-1486T/C polymorphism and 28 were mutant homozygous. In T2DM and CAD group, 71 of the 160 patients were heterozygous for TLR9-1486T/C polymorphism and 23 were mutant homozygous. In control group, 37 of the 66 patients were heterozygotes for TLR91486T/C polymorphism and 6 were mutant homozygotes. The frequencies of TLR-1486T/C genotypes and alleles were not significantly different between groups, respectively ( $P=0.642, P=0.962$, Table 3$)$.

We also examined several other TLR family gene variants that have been commonly reported in Western countries, including TLR9 promoter-1237T/C polymorphism, TLR2 Arg677Trp and Arg753Gln polymorphisms, and TLR4 Asp299Gly and Thr399Ile polymorphisms in all subjects. To our surprise, we did not detect the presence of any variant for these SNPs in our subjects (data not shown).

\section{Discussion}

It is well known that diabetes mellitus is not only a chronic inflammation disease, but also a disease of innate immune system. Long-term innate immune system activation, resulting in chronic inflammation, elicits disease in individuals who develop T2DM $[6,7]$. Schmidt et al. found that markers of inflammation, including total sialic acid (SA), orosomucoid, haptoglobin, and $\alpha 1$-antitrypsin, predict CAD and are increased in patients with T2DM [8]. Another study reported that markers of inflammation, such 
TABLE 3: Genotype distribution of TLR9-1486T/C promoter polymorphism.

\begin{tabular}{|c|c|c|c|c|c|c|}
\hline \multirow{2}{*}{ SNP } & \multicolumn{3}{|c|}{ Genotypes } & \multirow[t]{2}{*}{ Total } & \multicolumn{2}{|c|}{ Allele frequency } \\
\hline & TT & $\mathrm{TC}$ & $\mathrm{CC}$ & & $\mathrm{C}$ & $\mathrm{T}$ \\
\hline Non-CAD & 46 & 41 & 12 & 99 & $65(32.8 \%)$ & $133(67.2 \%)$ \\
\hline CAD & 135 & 147 & 51 & 333 & $249(37.4 \%)$ & $417(62.6 \%)$ \\
\hline$P$ & \multicolumn{4}{|c|}{$\chi^{2}=1.304 P=0.521$} & \multicolumn{2}{|c|}{$\chi^{2}=1.371 P=0.242$} \\
\hline Non-DM & 91 & 103 & 34 & 239 & $171(37.5 \%)$ & $285(62.5 \%)$ \\
\hline $\mathrm{DM}$ & 79 & 85 & 29 & 193 & $143(37 \%)$ & $243(63 \%)$ \\
\hline$P$ & \multicolumn{4}{|c|}{$\chi^{2}=0.058 P=0.971$} & \multicolumn{2}{|c|}{$\chi^{2}=0.018 P=0.892$} \\
\hline Control & 23 & 37 & 6 & 66 & $49(37.1 \%)$ & $83(62.9 \%)$ \\
\hline CAD & 69 & 76 & 28 & 173 & $132(38.2 \%)$ & $214(61.8 \%)$ \\
\hline $\mathrm{DM}$ & 13 & 14 & 6 & 33 & $26(39.4 \%)$ & $40(60.6 \%)$ \\
\hline $\mathrm{DM}+\mathrm{CAD}$ & 66 & 71 & 23 & 160 & $117(36.6 \%)$ & $203(63.4)$ \\
\hline$P$ & \multicolumn{4}{|c|}{$\chi^{2}=4.258 P=0.642$} & \multicolumn{2}{|c|}{$\chi^{2}=0.292 P=0.962$} \\
\hline
\end{tabular}

Control: control group; CHD: CAD group; DM: T2DM group; DM + CAD = type 2 diabetes mellitus plus coronary artery disease group.

TABLE 4: Comparison of TLR9-1486T/C promoter polymorphism in Asian population.

\begin{tabular}{lcccc}
\hline \multirow{2}{*}{ Nationality } & \multicolumn{4}{c}{ Genotype } \\
& TT & TC & CC & $P$ \\
\hline Hong Kong & $335(43.6 \%)$ & $350(45.5 \%)$ & $84(10.9 \%)$ & 0.256 \\
Japanese & $51(25.8 \%)$ & $108(54.5 \%)$ & $39(19.7 \%)$ & 0.093 \\
This study & $23(34.8 \%)$ & $37(56.1 \%)$ & $6(9.1 \%)$ & \\
\hline
\end{tabular}

as C-reactive protein (CRP) levels, white blood cell, and fibrinogen, were associated with the development of diabetes in the elderly [9]. In addition, the circulating inflammatory markers interleukin 6, acute-phase reactants, and especially CRP have been shown to predict the development of T2DM [10-12].

The concept of atherosclerosis being a chronic inflammation disease has been reviewed by Ross [13]. So far, many studies have demonstrated that atherosclerosis is an active, inflammatory process, rather than simply a passive infiltration of lipids [14-19]. T2DM is a common and potent risk factor for coronary artery disease. The presence of T2DM significantly increases the risk of atherosclerosis [2, 20-22] as our present study results corroborate. In a word, T2DM and atherosclerotic cardiovascular disease have common antecedents.

A homologous family of toll-like receptors (TLRs) was discovered in 1997 [23]. TLRs are differentially expressed among immune cells and serve as pattern-recognition receptors in mammals. They recognize and bind to conserved pathogen-associated molecular patterns shared by large groups of microorganisms and trigger the activation of signal transduction pathways, which in turn induce dendritic cell maturation and cytokine production [24]. These receptors play a central role in the activation of innate immunity [25]. A growing body of data supports a role of specific single nucleotide polymorphisms (SNPs) in several TLR genes in modulating the risk of bacterial and viral infections.

The relationship between inflammation, innate immunity, and diabetes was not fully understood. To prove whether inflammation contributes to the onset or progression of diabetes, we examined whether a constitutive defect in the innate immune response as occurs in the form of TLRs polymorphism was associated with reduced diabetes risk and its chronic macrovascular complication [26].

First, Our findings showed that there were three genotypes in TLR9 promoter-1486T/C position in Chinese Han population. The frequency of the $\mathrm{C}$ allele was $37.5 \%$. The genotype frequencies of the TLR9-1486T/C in Chinese Han population were similar to those of Koreans [27]. But exploratory analyses did not support the association between TLR9-1486T/C polymorphism and the prevalence of T2DM or angiographic coronary artery disease. Although no significant association was found, the CC genotype of TLR9-1486T/C tended to be overrepresented in patients with T2DM compared with controls $(18.2 \%$ versus $9.1 \%, P=$ $0.055)$. However, the frequency of $C$ allele in controls is not in line with the finding from Japanese population $(P=0.093$, Table 4) [28].

It was reported that Korea population had low frequency of TLR9-1237T/C $(<0.3 \%)$ [27]. No TLR9-1237T/C polymorphism was present in 183 patients with SLE and 198 controls in a Japanese population [28]. But high frequency of the variant allele was reported in the Caucasian population $(11-16 \%)$ [29]. The genetic variation at position-1237 is associated with an increased risk of asthma in European American populations [30]. However, we did not detect any SNP at position-1237 in our study, and Korean and Japanese populations and other Chinese population also have much less variations at position-1237 [27, 28, 31]. It would be very interesting to examine whether distinct TLR91237T/C genotype variations worldwide may be related to the disease patterns in these countries, especially considering the relatively low incident rate of heart diseases in the Oriental populations.

Many studies in Caucasians suggested that TLR4 polymorphisms were associated with innate immunityrelated diseases, such as chronic inflammatory disease and atherosclerosis [32-34]. One study showed that TLR4 Asp299Gly polymorphism was associated with reductions 
in vascular inflammation, angiographic coronary artery disease, and clinical diabetes in Caucasian populations [26]. A strong association between the TLR4 Asp299Gly/Thr399Ile polymorphism and diabetic neuropathy was showed in Rudofsky's study [35]. In contrast, TLR4 Asp299Gly and Thr399Ile polymorphisms were reported to be very rare in several studies of Asian ethic groups. Hang et al. failed to detect any homozygous or heterozygous variant genotypes of TLR4 Asp299Gly and Thr399Ile polymorphisms in 491 Han Chinese subjects, consisting of cotton and silk textile workers who was exposed to endotoxins [36]. In addition, almost no Asp299Gly were detected in ethnic Chinese patients in a study that analyzed the association of ischemic stroke with the TLR4 gene polymorphism [37].

In our study subjects, TLR2 Arg677Trp and Arg753Gln polymorphisms, TLR4 Asp299Gly and Thr399Ile polymorphisms, and TLR9-1237T/C mutation were all absent, in a complete agreement with studies in Japanese [38] and Korean population [39]. It is not clear whether the very low frequency of these TLR variants, as reported in this study, would be related to the low incident rates of diseases in the Orientals, such as diabetes and coronary artery disease compared with the western population. A large international study covering both developed countries and Asian populations that have varied TLR variations should be investigated to address this hypothesis.

Our study may have some limitations. Because it is a retrospective case-control study, a selection bias cannot be completely excluded. The study population was comprised entirely of patients. To limit this possibility we included consecutive patients and tried to adjust for known confounding risk factors. On the other hand, the strength of our study is that all subjects are of the same ethnic origin. Furthermore, all subjects were examined in a standardized manner, with well-defined diagnostic criteria. All genotyping was performed blind with respect to case-control status.

It should be noted that the occurrence of diabetes and/or its complications depends on the interaction among multiple risk factors, like the presence of different risk alleles, environmental factors, and the lifestyle. The contribution of any single-gene polymorphism is rather small and the interactive effect of several factors may lead to an underestimation or an overestimation of the role of a given polymorphism in determining the phenotype. Therefore, the results might not apply to groups with different genetic or environmental backgrounds. Despite the limitations of the study, the association between TLRs gene variant and susceptibility to T2DM and/or its complication will strengthen our understanding of the link between innate immunity, T2DM, and atherosclerosis.

In conclusion, the present study suggests that TLR91486T/C polymorphism may not be appropriate to predict the susceptibility to T2DM or CAD in Chinese Shanghai Han population. Like other Asian populations, Shanghai Han population has very low occurrence of other TLR SNPs, including TLR2 Arg677Trp and Arg753Gln polymorphisms, TLR4 Asp299Gly and Thr399Ile polymorphisms, and TLR9 promoter-1237T/C mutation, which is unlike western countries. Whether these unusually rare TLR variations are also related to distinct disease patterns in different racial population awaits further investigation.

$\begin{array}{ll}\text { Abbreviation } \\ \text { TLR: } & \text { Toll-like receptor } \\ \text { PCR-RFLP: } & \text { Polymerase chain reaction-restriction } \\ & \text { fragment length polymorphism } \\ \text { CAD: } & \text { Coronary artery disease } \\ \text { SNPs: } & \text { Single-nucleotide polymorphisms } \\ \text { WHO: } & \text { World Health Organization } \\ \text { T2DM: } & \text { Type 2 diabetes mellitus } \\ \text { SA: } & \text { Sialic acid } \\ \text { F: } & \text { Forward primer } \\ \text { R: } & \text { Reverse primer } \\ \text { AT: } & \text { Annealing temperature } \\ \text { RE: } & \text { Restriction enzyme } \\ \text { CRP: } & \text { C-reactive protein. }\end{array}$

\section{Conflict of Interests}

The authors declare they have no Conflict of interests.

\section{Authors' Contribution}

Each author contributed to the subject recruitment, data collection, laboratory work, statistical analysis, and paper writing. In addition, F. Liu designed and processed the study and wrote the first draft of the paper. J. Hu helped in the statistical analysis of the data and final paper writing. B. Feng conceived and supervised the study and critically evaluated the study and paper. All authors contributed to and approved the final paper. J. Hu and B. Feng contributes equally to this study.

\section{References}

[1] D. Lloyd-Jones, R. J. Adams, T. M. Brown et al., "Executive summary: heart disease and stroke statistics-2010 update: a report from the american heart association," Circulation, vol. 121, no. 7, pp. e46-e215, 2010.

[2] G. G. L. Biondi-Zoccai, A. Abbate, G. Liuzzo, and L. M. Biasucci, "Atherothrombosis, inflammation, and diabetes," Journal of the American College of Cardiology, vol. 41, no. 7, pp. 1071-1077, 2003.

[3] S. Akira, K. Takeda, and T. Kaisho, "Toll-like receptors: critical proteins linking innate and acquired immunity," Nature Immunology, vol. 2, no. 8, pp. 675-680, 2001.

[4] E. Andreakos, B. Foxwell, and M. Feldmann, "Is targeting Tolllike receptors and their signaling pathway a useful therapeutic approach to modulating cytokine-driven inflammation?" Immunological Reviews, vol. 202, pp. 250-265, 2004.

[5] N. W. J. Schröder and R. R. Schumann, "Single nucleotide polymorphisms of Toll-like receptors and susceptibility to infectious disease," The Lancet Infectious Diseases, vol. 5, no. 3, pp. 156-164, 2005.

[6] J. C. Pickup and M. A. Crook, "Is type II diabetes mellitus a disease of the innate immune system?" Diabetologia, vol. 41, no. 10, pp. 1241-1248, 1998. 
[7] T. Temelkova-Kurktschiev, E. Henkel, C. Koehler et al., "Subclinical inflammation in newly detected type II diabetes and impaired glucose tolerance," Diabetologia, vol. 45, no. 1, p. 151, 2002.

[8] M. I. Schmidt, B. B. Duncan, A. R. Sharrett et al., "Markers of inflammation and prediction of diabetes mellitus in adults (Atherosclerosis Risk in Communities study): a cohort study," The Lancet, vol. 353, no. 9165, pp. 1649-1652, 1999.

[9] J. I. Barzilay, L. Abraham, S. R. Heckbert et al., "The relation of markers of inflammation to the development of glucose disorders in the elderly: the cardiovascular health study," Diabetes, vol. 50, no. 10, pp. 2384-2389, 2001.

[10] J. C. Pickup, M. B. Mattock, G. D. Chusney, and D. Burt, "NIDDM as a disease of the innate immune system: association of acute- phase reactants and interleukin- 6 with metabolic syndrome X," Diabetologia, vol. 40, no. 11, pp. 1286-1292, 1997.

[11] A. D. Pradhan, J. E. Manson, N. Rifai, J. E. Buring, and P. M. Ridker, "C-reactive protein, interleukin 6, and risk of developing type 2 diabetes mellitus," Journal of the American Medical Association, vol. 286, no. 3, pp. 327-334, 2001.

[12] D. J. Freeman, J. Norrie, M. J. Caslake et al., "C-reactive protein is an independent predictor of risk for the development of diabetes in the west of Scotland coronary prevention study," Diabetes, vol. 51, no. 5, pp. 1596-1600, 2002.

[13] R. Ross, "Atherosclerosis is an inflammatory disease," American Heart Journal, vol. 138, no. 5, pp. S419-S420, 1999.

[14] R. Ross, "Atherosclerosis—an inflammatory disease," The New England Journal of Medicine, vol. 340, no. 2, pp. 115-126, 1999.

[15] P. Libby, P. M. Ridker, and A. Maseri, "Inflammation and atherosclerosis," Circulation, vol. 105, no. 9, pp. 1135-1143, 2002.

[16] J. S. Zebrack and J. L. Anderson, "The role of inflammation and infection in the pathogenesis and evolution of coronary artery disease," Current Cardiology Reports, vol. 4, no. 4, pp. 278-288, 2002.

[17] T. A. Pearson, G. A. Mensah, R. W. Alexander et al., "Markers of inflammation and cardiovascular disease: application to clinical and public health practice: a statement for healthcare professionals from the centers for disease control and prevention and the American Heart Association," Circulation, vol. 107, no. 3, pp. 499-511, 2003.

[18] P. M. Ridker, "Clinical application of C-reactive protein for cardiovascular disease detection and prevention," Circulation, vol. 107, no. 3, pp. 363-369, 2003.

[19] V. Fuster, "Lewis A. Conner memorial lecture: mechanisms leading to myocardial infarction: insights from studies of vascular biology," Circulation, vol. 90, no. 4, pp. 2126-2146, 1994.

[20] Expert Committee on the Diagnosis and Classification of Diabetes Mellitus, "Report of the expert committee on the diagnosis and classification of diabetes mellitus," Diabetes Care, vol. 26, supplement 1, pp. S5-S20, 2003.

[21] S. M. Grundy, B. Howard, S. Smith Jr., R. Eckel, R. Redberg, and R. O. Bonow, "Prevention conference VI: diabetes and cardiovascular disease-executive summary: conference proceeding for healthcare professionals from a special writing group of the American Heart Association," Circulation, vol. 105, no. 18, pp. 2231-2239, 2002.

[22] J. W. Baynes and S. R. Thorpe, "Role of oxidative stress in diabetic complications: a new perspective on an old paradigm," Diabetes, vol. 48, no. 1, pp. 1-9, 1999.
[23] R. Medzhitov, P. Preston-Hurlburt, and C. A. Janeway Jr., "A human homologue of the Drosophila toll protein signals activation of adaptive immunity," Nature, vol. 388, no. 6640, pp. 394-397, 1997.

[24] S. Akira, S. Uematsu, and O. Takeuchi, "Pathogen recognition and innate immunity," Cell, vol. 124, no. 4, pp. 783-801, 2006.

[25] S. Uematsu and S. Akira, "Toll-like receptors and innate immunity," Journal of Molecular Medicine, vol. 84, no. 9, pp. 712-725, 2006.

[26] M. J. Kolek, J. F. Carlquist, J. B. Muhlestein et al., “Toll-like receptor 4 gene Asp299Gly polymorphism is associated with reductions in vascular inflammation, angiographic coronary artery disease, and clinical diabetes," American Heart Journal, vol. 148, no. 6, pp. 1034-1040, 2004.

[27] J. W. Hur, H. D. Shin, B. L. Park, L. H. Kim, S. Y. Kim, and S. C. Bae, "Association study of Toll-like receptor 9 gene polymorphism in Korean patients with systemic lupus erythematosus," Tissue Antigens, vol. 65, no. 3, pp. 266-270, 2005.

[28] K. Tao, M. Fujii, S. I. Tsukumo et al., "Genetic variations of Toll-like receptor 9 predispose to systemic lupus erythematosus in Japanese population," Annals of the Rheumatic Diseases, vol. 66, no. 7, pp. 905-909, 2007.

[29] G. L. Hold, C. S. Rabkin, M. D. Gammon et al., "CD14159C/T and TLR9-1237T/C polymorphisms are not associated with gastric cancer risk in Caucasian populations," European Journal of Cancer Prevention, vol. 18, no. 2, pp. 117-119, 2009.

[30] R. Lazarus, W. T. Klimecki, B. A. Raby et al., "Single-nucleotide polymorphisms in the Toll-like receptor 9 gene (TLR9): frequencies, pairwise linkage disequilibrium, and haplotypes in three U.S. ethnic groups and exploratory case-control disease association studies," Genomics, vol. 81, no. 1, pp. 8591, 2003.

[31] M. W. Ng, C. S. Lau, T. M. Chan, W. H. S. Wong, and Y. L. Lau, "Polymorphisms of the toll-like receptor 9 (TLR9) gene with systemic lupus erythematosus in Chinese," Rheumatology, vol. 44, no. 11, pp. 1456-1457, 2005.

[32] S. Kiechl, E. Lorenz, M. Reindl et al., "Toll-like receptor 4 polymorphisms and atherogenesis," The New England Journal of Medicine, vol. 347, no. 3, pp. 185-192, 2002.

[33] S. C. G. Hollestelle, M. R. De Vries, J. K. Van Keulen et al., "Toll-like receptor 4 is involved in outward arterial remodeling," Circulation, vol. 109, no. 3, pp. 393-398, 2004.

[34] S. M. Boekholdt, W. R. P. Agema, R. J. G. Peters et al., "Variants of toll-like receptor 4 modify the efficacy of statin therapy and the risk of cardiovascular events," Circulation, vol. 107, no. 19, pp. 2416-2421, 2003.

[35] G. Rudofsky Jr., P. Reismann, S. Witte et al., "Asp299Gly and Thr399Ile genotypes of the TLR4 gene are associated with a reduced prevalence of diabetic neuropathy in patients with type 2 diabetes," Diabetes Care, vol. 27, no. 1, pp. 179-183, 2004.

[36] J. Hang, W. Zhou, H. Zhang et al., "TLR4 Asp299Gly and Thr399Ile polymorphims are very rare in the Chinese population," Journal of Endotoxin Research, vol. 10, no. 4, pp. 238-240, 2004.

[37] Y. C. Lin, Y. M. Chang, J. M. Yu, J. H. Yen, J. G. Chang, and C. J. Hu, "Toll-like receptor 4 gene C119A but not Asp299Gly polymorphism is associated with ischemic stroke among ethnic Chinese in Taiwan," Atherosclerosis, vol. 180, no. 2, pp. 305-309, 2005.

[38] T. A. Nakada, H. Hirasawa, S. Oda et al., "Influence of toll-like receptor 4, CD14, tumor necrosis factor, and interleukine-10 gene polymorphisms on clinical outcome in Japanese critically 
ill patients," Journal of Surgical Research, vol. 129, no. 2, pp. 322-328, 2005.

[39] Y. S. Kim, Y. J. Hwang, S. Y. Kim, S. M. Yang, K. Y. Lee, and I. B. Park, "Rarity of TLR4 Asp299Gly and Thr399Ile polymorphisms in the Korean population," Yonsei Medical Journal, vol. 49, no. 1, pp. 58-62, 2008. 


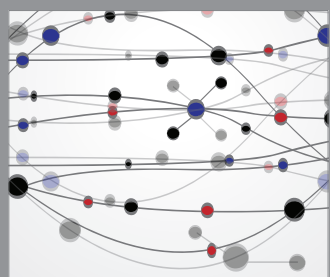

The Scientific World Journal
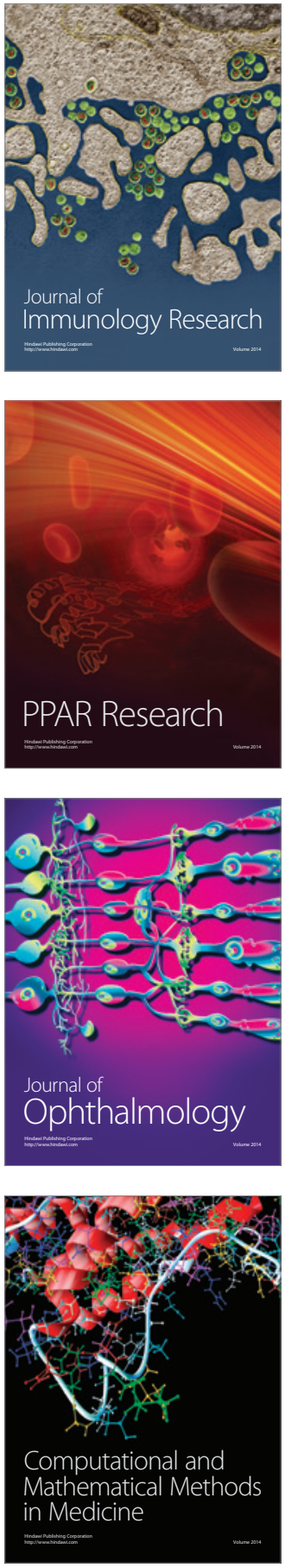

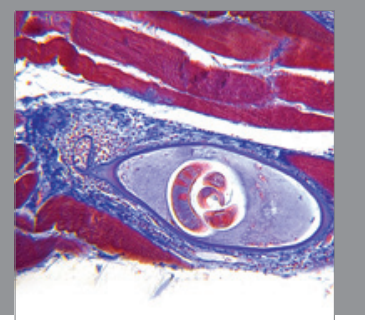

Gastroenterology

Research and Practice
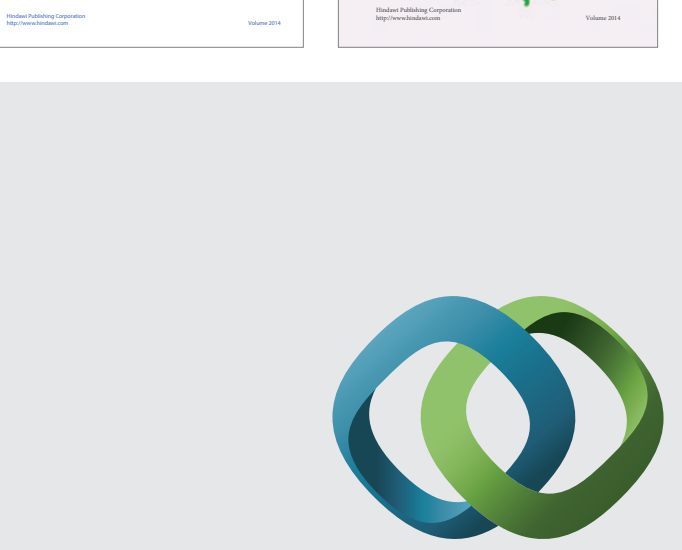

\section{Hindawi}

Submit your manuscripts at

http://www.hindawi.com
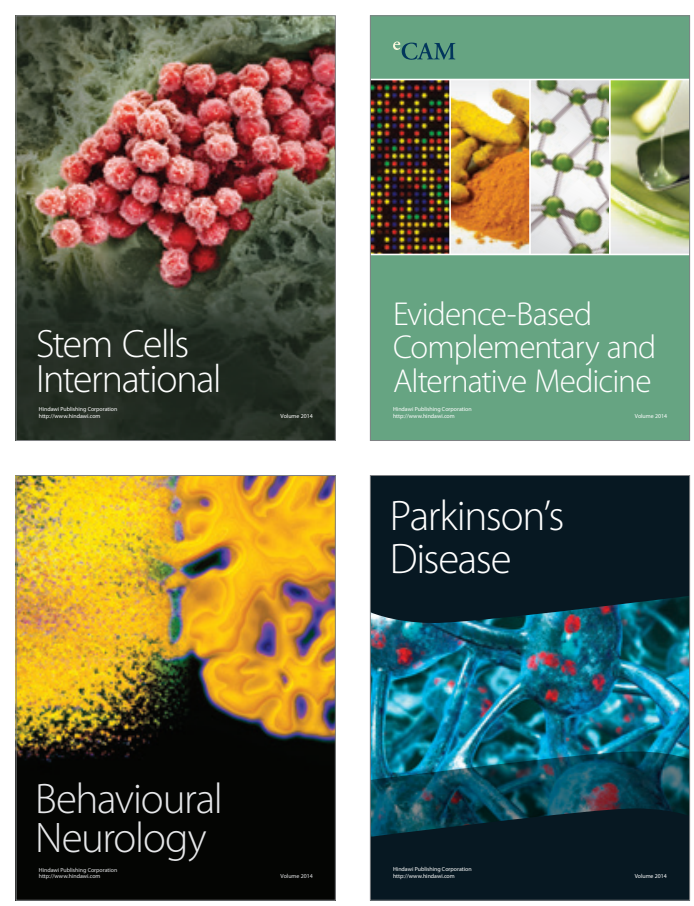

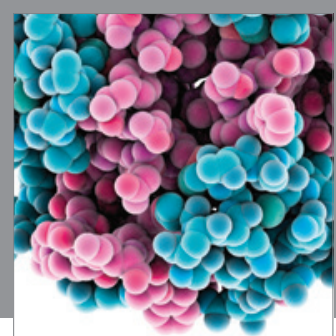

Journal of
Diabetes Research

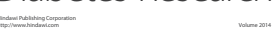

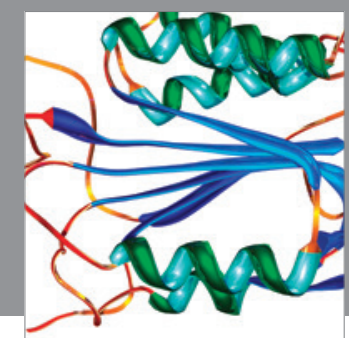

Disease Markers
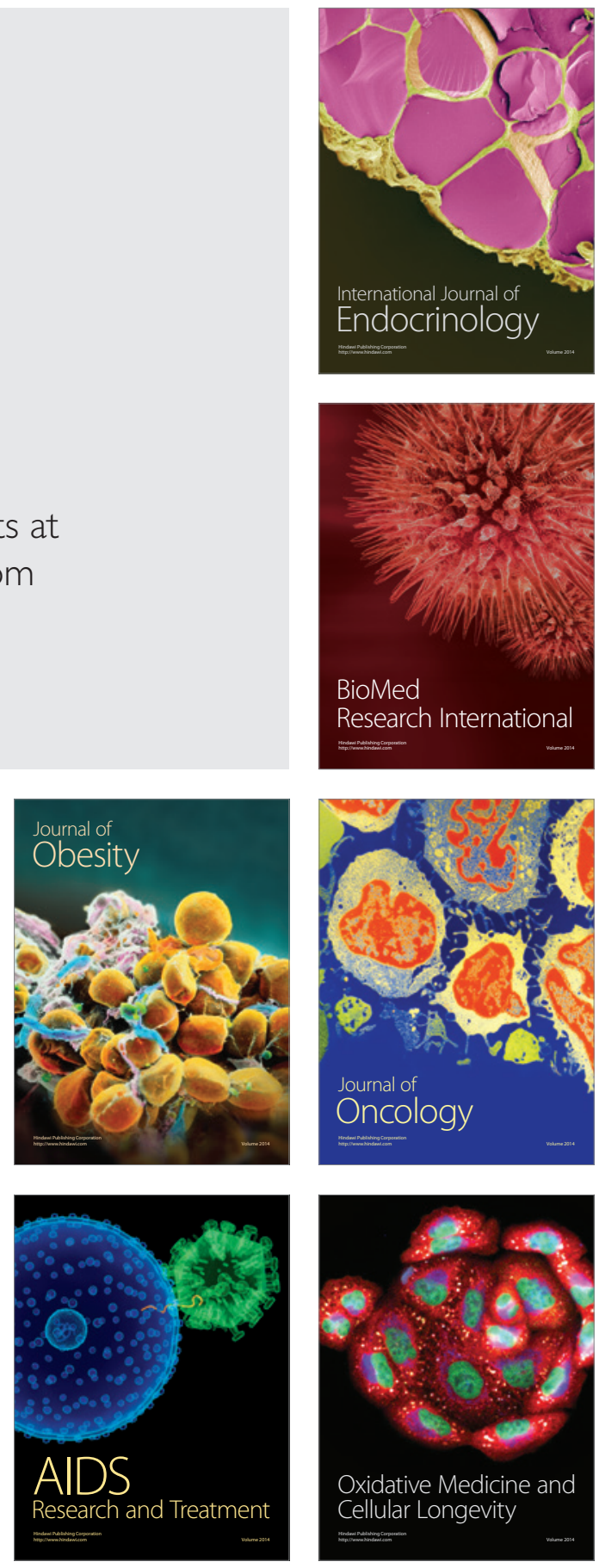